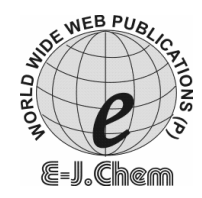

\title{
Utility of $\sigma$ and $\pi$-Acceptors for the Spectrophotometric Determination of Gemifloxacin Mesylate in Pharmaceutical Formulations
}

\author{
MAROTHU VAMSI KRISHNA* and DANNANA GOWRI SANKAR \\ Pharmaceutical Analysis and Quality Assurance Division, \\ College of Pharmaceutical Sciences, \\ Andhra University, Visakhapatnam, India. \\ marothu_vamsi@rediffmail.com
}

Received 16 April 2007; Accepted 10 June 2007

\begin{abstract}
In this study, four simple, fast, accurate and sensitive spectrophotometric methods have been developed for the determination of gemifloxacin mesylate in pharmaceutical formulations. The methods are based on the charge transfer complexation reaction of the drug as n-electron donor with sigma $(\sigma)$-acceptor iodine, and the pi $(\pi)$-acceptors 2,3 -dichloro-5, 6dicyano- $p$-benzoquinone (DDQ)-7,7,8,8-tetra cyanoquinodimethane (TCNQ) and tetracyanoethylene (TCNE). The obtained charge transfer complexes were measured at 290nm for iodine (in 1, 2-dichloro ethane), at 470, 840 and 420 $\mathrm{nm}$ for DDQ, TCNQ and TCNE (in acetonitrile), respectively. Optimization of different experimental conditions is described. Beer's law is obeyed in the concentration range of 6-30, 2-10, 2.5-12.5 and 1-5 $\mu \mathrm{g} \mathrm{mL}^{-1}$ for iodine, DDQ, TCNQ and TCNE methods, respectively. The proposed methods were applied successfully to the determination of GFX in pharmaceutical formulations with good accuracy and precision.
\end{abstract}

Keywords: $\sigma$ and $\pi$-acceptors, Spectrophotometric determination, Gemifloxacin mesylate.

\section{Introduction}

Gemifloxacin, (R,S)-7-(3-aminomethyl-4-syn-methoxyimino-1-pyrrolidinyl)-1-cyclopropyl6-fluoro-1,4-dihydro-4-oxo-1,8-naphthyridine-3-carboxylic acid methanesulfonate, is a new fluoroquinolone antibacterial compound with enhanced affinity for bacterial topoisomerase IV and is being developed for the treatment of respiratory and urinary tract infections. The compound has a broad spectrum of activity against Gram-positive and Gram-negative bacteria $^{1-3}$. Literature survey revealed that few analytical methods have been reported for the estimation of GFX; they include high - performance liquid chromatography-tandem mass 
spectrometry (LC-MS-MS) ${ }^{4-5}$, microchip electrophoresis ${ }^{6}$, chiral high-performance liquid chromatography ${ }^{7}$ and chiral counter-current chromatography ${ }^{8}$. To the best of our nowledge, there is no work in the literature reported about the spectrophotometric method for the analysis of GFX in either biological fluids or pharmaceutical formulations. Hence the author has made an attempt to develop four simple and rapid spectrophotometric methods for the estimation of GFX in bulk drugs and in pharmaceutical formulations.

The molecular interactions between electron donors and acceptors are generally associated with the formation of intensity colored charge transfer complexes, which absorbs radiation in the visible region ${ }^{9}$. The photometric methods based on these interactions are usually simple and convenient because of the rapid formation of the complexes. GFX is good electron donor and will form charge-transfer complexes with sigma or $p i$-acceptors.

$p i$-Acceptors such as DDQ, TCNQ and TCNE are known to yield charge-transfer complexes and radical anions with a variety of electron donors ${ }^{9-11}$. This study describes simple, direct, sensitive, accurate and precise spectrophotometric methods for the determination of GFX via reaction with sigma and pi-acceptors in the common dosage forms and irrespective of the presence of contaminants and additives.

\section{Experimental}

Apparatus

All spectral and absorbance measurements were made on a systronic model 117 digital spectrophotometer with $10 \mathrm{~mm}$ matched quartz cells

\section{Materials and reagents}

All chemicals used were of analytical reagent grade. Iodine (resublimed) was $25.5 \mathrm{mg}$ per $50 \mathrm{~mL}$ in 1, 2-dichloroethane. The solution was found to be stable for at least 1 week at $5^{0} \mathrm{C}$. DDQ (2, 3-dichloro-5, 6-dicyano- $p$-benzoquinone) was $2 \mathrm{mg} / \mathrm{mL}$ in acetonitrile. The solution was prepared fresh daily. TCNQ (7, 7, 8, 8-tetra cyanoquinodimethane) was $1 \mathrm{mg} / \mathrm{mL}$ in acetonitrile. The solution was found to be stable for at least 1 week at $5^{\circ} \mathrm{C}$. TCNE (tetracyanoethylene) was $2 \mathrm{mg} / \mathrm{mL}$ in acetonitrile. The solution was prepared fresh daily.

\section{Preparation of standard stock solutions}

Into a $100 \mathrm{~mL}$ calibrated flask, $50 \mathrm{mg}$ drug was weighed accurately and dissolved in $10 \mathrm{~mL}$ of acetonitrile, completed to volume with the same solvent ( for DDQ, TCNQ and TCNE) and with 1,2-dichloroethane (for iodine), and diluted quantitatively to obtain the suitable concentrations.

\section{General procedures and calibration graphs}

\section{Method using iodine}

Aliquots of GFX $\left(0.6-3 \mathrm{~mL} ; 100 \mu \mathrm{g} \mathrm{mL}^{-1}\right)$ were transferred into a $10 \mathrm{~mL}$ calibrated flasks, treated with $1 \mathrm{~mL}$ iodine solution, allowed to stand for $5 \mathrm{~min}$ at $25 \pm 5^{\circ} \mathrm{C}$ and diluted to volume with 1, 2 dichloroethane. The absorbance was measured at $290 \mathrm{~nm}$ against a reagent blank. The calibration graph was then prepared by plotting the absorbance versus concentration of the drug. The concentration of the unknown was read from the calibration graph or computed from the regression equation. 


\section{Method using $D D Q$}

Aliquots of GFX $\left(0.2-1 \mathrm{~mL} ; 100 \mu \mathrm{g} \mathrm{mL}^{-1}\right)$ were transferred into a $10 \mathrm{~mL}$ calibrated flasks, treated with $1 \mathrm{~mL}$ DDQ solution, allowed to stand for $20 \mathrm{~min}$ at $25 \pm 5^{\circ} \mathrm{C}$ and diluted to volume with acetonitrile. The absorbance was measured at $470 \mathrm{~nm}$ against a reagent blank. The calibration graph was then prepared by plotting the absorbance versus concentration of the drug. The concentration of the unknown was read from the calibration graph or computed from the regression equation.

\section{Method using TCNQ}

Aliquots of GFX $\left(0.5-2.5 \mathrm{~mL} ; 50 \mu \mathrm{g} \mathrm{mL}^{-1}\right)$ were transferred into a $10 \mathrm{~mL}$ calibrated flasks, treated with $2 \mathrm{~mL}$ TCNQ solution, allowed to stand for $40 \mathrm{~min}$ at $25 \pm 5^{\circ} \mathrm{C}$ and diluted to volume with acetonitrile. The absorbance was measured at $840 \mathrm{~nm}$ against a reagent blank. The calibration graph was then prepared by plotting the absorbance versus concentration of the drug. The concentration of the unknown was read from the calibration graph or computed from the regression equation.

\section{Method using TCNE}

Aliquots of GFX $\left(0.2-1.0 \mathrm{~mL} ; 50 \mu \mathrm{g} \mathrm{mL}^{-1}\right)$ were transferred into a $10 \mathrm{~mL}$ calibrated flasks, treated with $1.5 \mathrm{~mL}$ TCNE solution, allowed to stand for $45 \mathrm{~min}$ at $25 \pm 5^{\circ} \mathrm{C}$ and diluted to volume with acetonitrile. The absorbance was measured at $420 \mathrm{~nm}$ against a reagent blank. The calibration graph was then prepared by plotting the absorbance versus concentration of the drug. The concentration of the unknown was read from the calibration graph or computed from the regression equation.

\section{Procedure for the assay of the tablets}

20 tablets were weighed and an accurately weighed amount of the finely powdered tablets equivalent to $50 \mathrm{mg}$ of GFX was transferred into a $50 \mathrm{~mL}$ calibrated flask, $5 \mathrm{~mL}$ acetonitrile was added. The solution was shaken for $5 \mathrm{~min}$ to dissolve the drug. The volume was made up to $50 \mathrm{~mL}$ with acetonitrile (for DDQ, TCNQ and TCNE) and with 1, 2-dichloroethane for iodine method. The solution was filtered using Whatman filter paper \#42 and the first few milliliters of the filtrate were discarded. The procedure was continued as mentioned under general procedure and calibration graphs.

\section{Results and Discussion}

\section{Reaction with sigma acceptor: Iodine}

Some $n$-donor drugs react with sigma electron acceptor iodine forming charge-transfer complex followed by tri- iodide ion pair formation ${ }^{12-13}$. Charge transfer complexes formed have a high absorption band at $290 \mathrm{~nm}$ and a lower band has a maximum at $365 \mathrm{~nm}$ followed by the formation of tri- iodide ion pair which is accompanied by variation in maximum absorption to wavelength ranging from 270 to $310 \mathrm{~nm}^{12}$. It is suggested that the cited drug reacts with iodine to form a tri-iodide ion pair with higher band absorption at 290 $\mathrm{nm}$ and a lower band at $365 \mathrm{~nm}$.

The immediate change of the violet color of iodine in 1, 2-dichloroethane $(520 \mathrm{~nm})$ to a lemon yellow upon reaction with the GFX was taken as suggestive of charge transfer complex formation. Further conformation of the charge-transfer nature of the reaction was obtained on extracting the drug from the complex by shaking with aqueous mineral acid, whereby the violet color of iodine in 1, 2-dichloroethane was restored.1, 2-dichloroethane 
was found to be an ideal solvent for the formation of a tri-iodide ion pair (inner complex). Methylene chloride, chloroform and carbon tetrachloride produced low absorbance readings. Polar solvents were found to be unsuitable as their blanks with iodine gave high absorbances.

\section{Reaction with pi-acceptors}

\section{Reaction with $D D Q$}

The interaction of GFX with DDQ in acetonitrile at room temperature gave an orange-red chromogen with a strong absorption maximum at $470 \mathrm{~nm}$.

\section{Reaction with TCNQ}

The reaction of TCNQ with GFX in acetonitrile solution was found to yield a deep color causing characteristic long wavelength absorption band. The predominant chromogen with TCNQ is blue colored radical anion, which probably resulted through the dissociation of an original donor-acceptor (DA) complex with the drug. This complex is formed by the lone pair of electrons donated by the GFX as $n$-donor and the TCNQ as an electron acceptor; a partial ionic bond $\left(\mathrm{D}^{+} \mathrm{A}^{-}\right)$is assumed to be formed. The dissociation of DA complex was promoted by the high ionizing power of the solvent, acetonitrile ${ }^{14}$.

\section{Reaction with TCNE}

In addition to DDQ \& TCNQ radical anions, the reaction of GFX with TCNE results in the development of yellow complex with 2 maxima at 390 and $420 \mathrm{~nm}$.

As assay solvent (for DDQ, TCNQ and TCNE methods) acetonitrile, benzene, chloroform, ethylene chloride and methylene chloride were examined. Acetonitrile afforded the maximum sensitivity when compared with all other solvents. This is because it possesses the highest dielectric constant of all solvents examined, a property which is known to promote the dissociation of the original charge-transfer complexes to the radical ions. Methylene chloride is a possible candidate, although it suffers from its low boiling point which could results in fluctuations of concentration during handling and manipulation. Benzene and chloroform were unsuitable owing to the limited solubility of the reagents.

\section{Effect of time (Rate of complex formation)}

The optimum reaction time was determined by following the color development at ambient temperature. For reaction with iodine the color was produced in 5 min upon mixing the contents of the flask. Complete color development was attained after 20, 40 and 45 min for DDQ, TCNQ and TCNE, respectively.

\section{Interference study}

To study the potential interference problems from the commonly used excipients and other additives such as microcrystalline cellulose, talc, lactose, sodium starch glycolate, povidone, gelatin, starch and magnesium stearate, recovery studies were carried out under the experimental conditions employed, to a known amount of drug (GFX $8.0 \mu \mathrm{g} \mathrm{mL}^{-1}$ for iodine, DDQ and TCNQ; GFX $3 \mu \mathrm{g} \mathrm{mL}{ }^{-1}$ for TCNE), excipients in different concentrations were added and analyzed. Results of recovery analysis are presented in Table 1. Excipients up to the concentrations shown in Table 1 do not interfere with the assay. In addition recoveries in most cases were around $100 \%$ and the lower values of the relative standard deviation (RSD) indicate good precision of the method. 
Table 1. Determination of GFX in the presence of excipients

\begin{tabular}{lccccc}
\hline \multirow{2}{*}{ Excipients } & $\begin{array}{c}\text { Amount } \\
\text { Taken }\end{array}$ & \multicolumn{4}{c}{ \% Recovery of GFX $\pm \%$ RSD } \\
\cline { 3 - 6 } & $\mu \mathrm{g} \mathrm{mL} \mathrm{m}^{-1}$ & $\begin{array}{c}\text { Iodine } \\
\text { Method }\end{array}$ & $\begin{array}{c}\text { DDQ } \\
\text { Method }\end{array}$ & $\begin{array}{c}\text { TCNQ } \\
\text { Method }\end{array}$ & $\begin{array}{c}\text { TCNE } \\
\text { Method }\end{array}$ \\
\hline Magnesium stearate & 50 & $99.3 \pm 0.46$ & $99.2 \pm 0.39$ & $99.6 \pm 0.31$ & $99.5 \pm 0.40$ \\
Micro crystalline & 300 & $100.2 \pm 0.35$ & $100.8 \pm 0.27$ & $100.5 \pm 0.44$ & $100.5 \pm 0.39$ \\
Cellulose & & & & & \\
Talc & 50 & $100.04 \pm 0.48$ & $100.1 \pm 0.25$ & $99.6 \pm 0.30$ & $99.9 \pm 0.21$ \\
Lactose & 300 & $99.52 \pm 0.52$ & $99.6 \pm 0.38$ & $99.9 \pm 0.45$ & $99.8 \pm 0.45$ \\
Sodium starch & 100 & $100.03 \pm 0.64$ & $101.2 \pm 0.30$ & $100.8 \pm 0.28$ & $100.6 \pm 0.33$ \\
Glycolate & & & & & \\
Povidone & 50 & $99.8 \pm 0.52$ & $99.7 \pm 0.49$ & $99.9 \pm 0.40$ & $100.0 \pm 0.25$ \\
Gelatin & 300 & $98.65 \pm 0.66$ & $99.9 \pm 0.40$ & $99.7 \pm 0.35$ & $99.9 \pm 0.52$ \\
Starch & 200 & $99.3 \pm 0.48$ & $99.2 \pm 0.35$ & $99.4 \pm 0.52$ & $99.7 \pm 0.42$ \\
\hline
\end{tabular}

*average of five determinations

The optical characteristics such as Beer's law limits, Sandell's sensitivity, molar absorptivity, percent relative standard deviation (calculated from eight replicate samples containing $3 / 4^{\text {th }}$ of the amount of the upper beer's law limits) were calculated for all the methods and the results are summarized in Table 2. Regression characteristics like standard deviation of slope $\left(S_{b}\right)$, standard deviation of intercept $\left(S_{a}\right)$, standard error of estimation $\left(S_{e}\right), \%$ range of error ( 0.05 and 0.01 confidence limits) and detection limits were calculated for all the methods and are shown in Table 2. Commercial formulation of GFX was successfully analyzed by the proposed methods. The values obtained by the proposed methods are presented in Table 3 .

Table 2. Optical, regression characteristics of the proposed methods for GFX

\begin{tabular}{|c|c|c|c|c|}
\hline Parameter & Iodine & DDQ & TCNQ & TCNE \\
\hline$\lambda_{\max } \mathrm{nm}$ & 290 & 470 & 840 & 420 \\
\hline Beer's law limits, $\mu \mathrm{g} \mathrm{mL} \mathrm{L}^{-1}$ & $6.0-30.0$ & $2.0-10.0$ & $2.5-12.5$ & $1.0-5.0$ \\
\hline Detection limits, $\mu \mathrm{g} \mathrm{mL}^{-1}$ & 0.124 & 0.063 & 0.098 & 0.021 \\
\hline Molar absorptivity, $\mathrm{L} \mathrm{mole}^{-1} \mathrm{~cm}^{-1}$ & $1.46 \times 10^{4}$ & $4.17 \times 10^{4}$ & $3.42 \times 10^{4}$ & $8.41 \times 10^{4}$ \\
\hline Sandell's sensitivity, $\mu \mathrm{g} \mathrm{cm}^{-2} /$ & 0.033 & 0.0116 & 0.014 & 0.005 \\
\hline \multicolumn{5}{|l|}{0.001 absorbance unit) } \\
\hline \multicolumn{5}{|l|}{ Regression equation $(\mathrm{Y}=\mathrm{a}+\mathrm{bC})$} \\
\hline Slope (b) & $3.0 \times 10^{-2}$ & $8.6 \times 10^{-2}$ & $7.0 \times 10^{-2}$ & $1.73 \times 10^{-1}$ \\
\hline Standard deviation of slope $\left(\mathrm{S}_{\mathrm{b}}\right)$ & $0.6 \times 10^{-4}$ & $0.28 \times 10^{-3}$ & $0.28 \times 10^{-3}$ & $0.38 \times 10^{-3}$ \\
\hline Intercept (a) & $0.70 \times 10^{-3}$ & $-0.90 \times 10^{-3}$ & $-0.90 \times 10^{-3}$ & $-0.30 \times 10^{-3}$ \\
\hline Standard deviation of intercept $\left(\mathrm{S}_{\mathrm{a}}\right)$ & $1.26 \times 10^{-3}$ & $1.83 \times 10^{-3}$ & $2.32 \times 10^{-3}$ & $1.26 \times 10^{-3}$ \\
\hline Standard error of estimation $\left(\mathrm{S}_{\mathrm{e}}\right)$ & $1.20 \times 10^{-3}$ & $1.74 \times 10^{-3}$ & $2.21 \times 10^{-3}$ & $1.20 \times 10^{-3}$ \\
\hline Correlation coefficient (r) & 0.9999 & 0.9999 & 0.9999 & 0.9999 \\
\hline Relative standard deviation, $\%^{a}$ & 0.097 & 0.121 & 0.105 & 0.107 \\
\hline \multicolumn{5}{|l|}{$\%$ Range of error(Confidence limits) ${ }^{a}$} \\
\hline 0.05 level & 0.081 & 0.102 & 0.088 & 0.090 \\
\hline 0.01 level & 0.120 & 0.150 & 0.130 & 0.133 \\
\hline$\%$ Error in bulk samples ${ }^{b}$ & -0.172 & 0.127 & 0.053 & -0.054 \\
\hline
\end{tabular}

${ }^{a}$ Average of eight determinations. ${ }^{b}$ Average of three determinations In $Y=a+b C, Y$ is absorbance and $C$ is concentration 
Table 3. Determination of GFX in pharmaceutical formulations by the proposed methods

\begin{tabular}{|c|c|c|c|c|c|c|c|c|c|}
\hline \multirow{2}{*}{ Formulation } & \multirow{2}{*}{$\begin{array}{c}\text { Labeled } \\
\text { Amount, mg }\end{array}$} & \multicolumn{4}{|c|}{ \% Recovery* } & & \multicolumn{3}{|c|}{ \% RSD } \\
\hline & & Iodine & DDQ & TCNQ & TCNE & Iodine & DDQ & TCNQ & TCNE \\
\hline Tablets-1 & 320 & 99.89 & 00.09 & 99.99 & 100.06 & 0.48 & 0.66 & 0.39 & 0.45 \\
\hline Tablets- 2 & 320 & 99.86 & 00.05 & 100.25 & 100.08 & 0.52 & 0.58 & 0.43 & 0.56 \\
\hline
\end{tabular}

* Average of five independent analyses

\section{Conclusion}

From the aforementioned results, the suggested procedures using sigma and pi-acceptors confirm their suitability for spectrophotometric analysis of GFX in the micro range. Moreover, they could be applied to the quality control analysis of the investigated drug.

\section{References}

1. Oh J I, Pack M J, Ahn M Y, Kim CY, Hong C Y, Kim I C and Kwak J H. Antimicrob Agents Chemother. 1996, 40, 1564.

2. Cormican M G and Jones R N, Antimicrob Agents Chemother. 1997, 41, 204.

3. Hohl A F, Frei R, Ponter V, Von graevenitz A, Knapp C, Washington J, Johnson D and Jones R N. Clin. Microbiol Infect. 1998, 4, 280.

4. Doyle E, Fowles S E, Mc Donnell D F, Mc Carthy and White S A. J. Chromatogr. B. 2000, 746, 191.

5. Ramji J V, Austin N E, Boyle G W, Chalker M H, Duncan G, Fairless A J, Hollis F J, Mc Donnell D F, Musick T J and Shardlow P C. Drug Metabolisam and Disposition. 2001, 29, 435.

6. Seung I Cho, Jiyeon Shim, Min-su kim, Yong-kweon kim and Doo soo chung. J. Chromatogr. A. 2004, 1055, 241.

7. Won jae Lee and Chang Yang Hong. J. Chromatogr. A. 2000, 879, 113.

8. Eun sook kim, Yoo-mo koo and Doo soo chung. J.Chromatogr. A. 2004, 1045, 119.

9. Foster R, Organic charge transfer complexes, Academic press, London, 1969, pp 51, 387.

10. Melby L R, in: Patai S. The chemistry of the cyano group Ed., Interscience, New York. 1970, 639-670.

11. Rao C N R, Bhat S N, Dwivedi P C, in: Brame E G, Ed., Applied Spectroscopy Reviews, Dekker, New York, 1972, 5, 1-170.

12. Lories I B, Naglaa E L K, Jihan K S, Mohamed S. J. Pharma. Biomed, Analysis. 1991, 21, 133.

13. Magda M A, Saied B, Adi Sobhi M E L and Afaf A K. Analyst, 1984, 109, 1417.

14. Hassan F A A, Gamal S and Nabil M O. Analyst, 1991, 116, 387. 


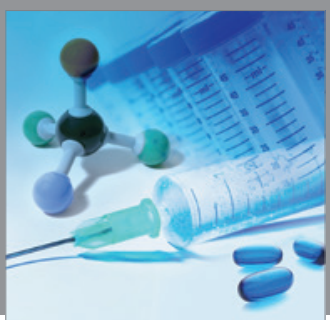

International Journal of

Medicinal Chemistry

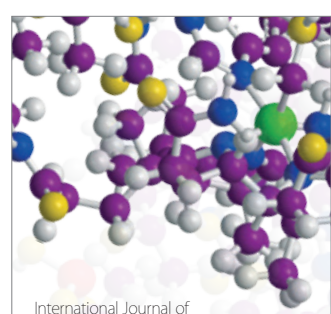

Carbohydrate Chemistry

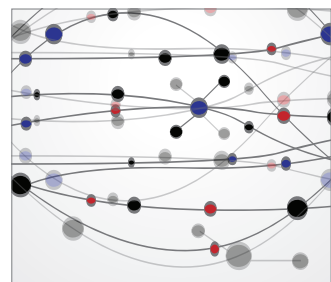

The Scientific World Journal
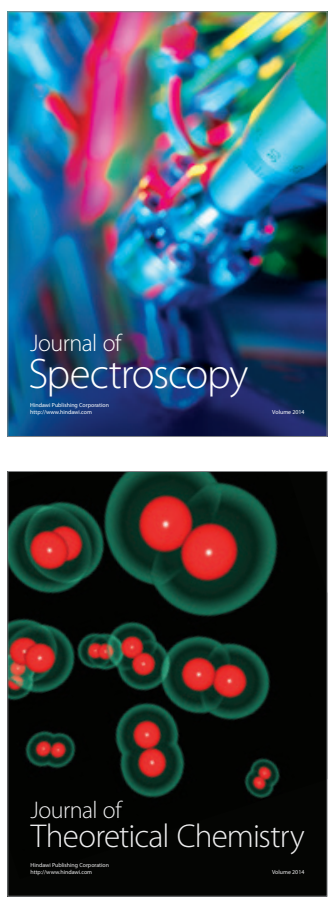
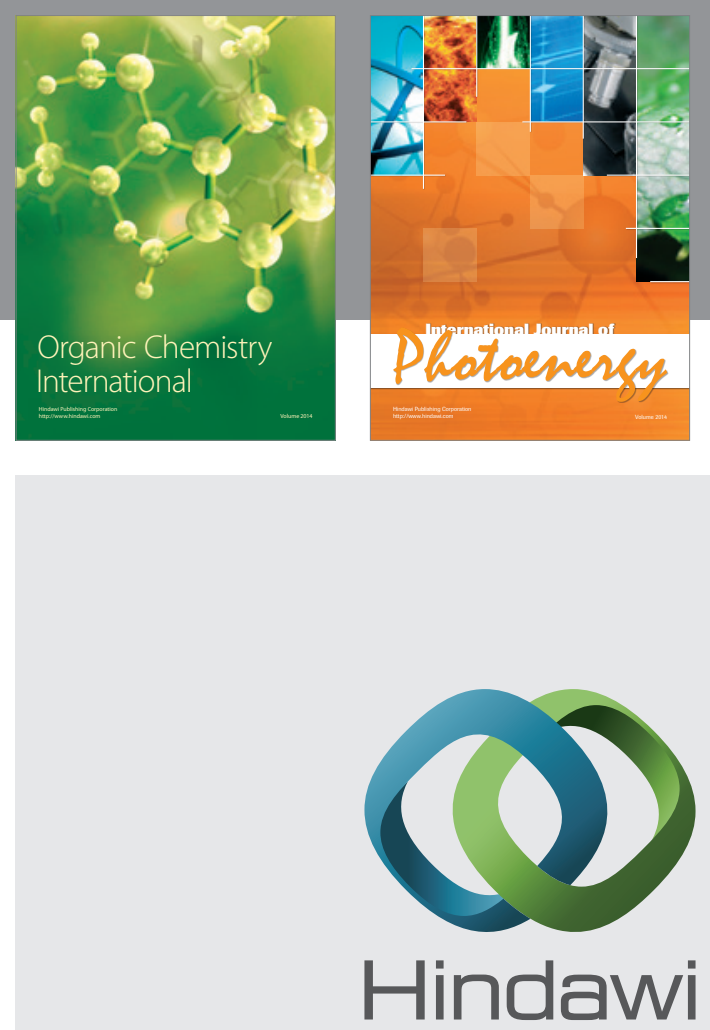

Submit your manuscripts at

http://www.hindawi.com
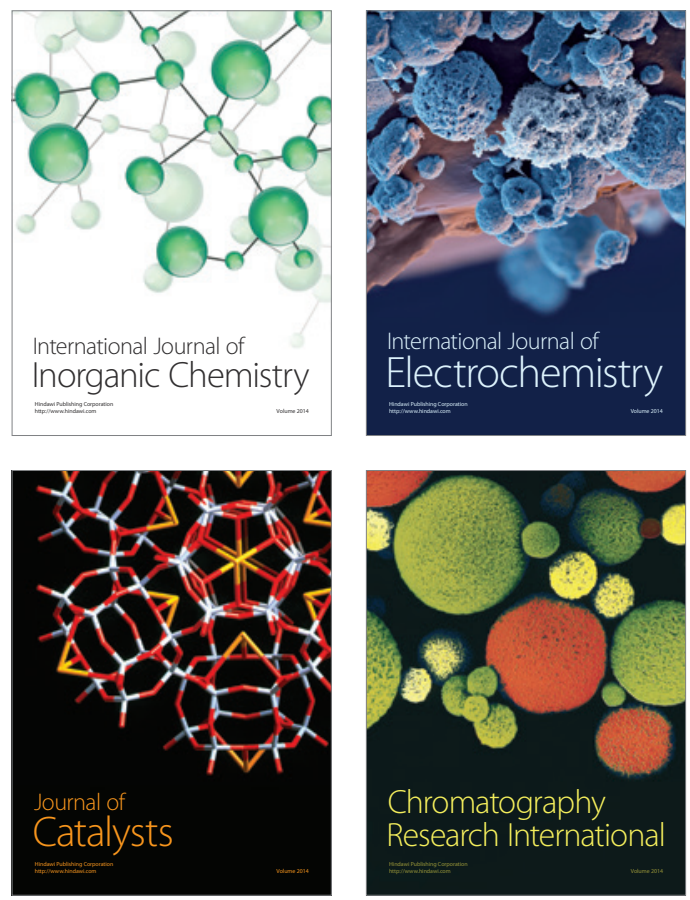
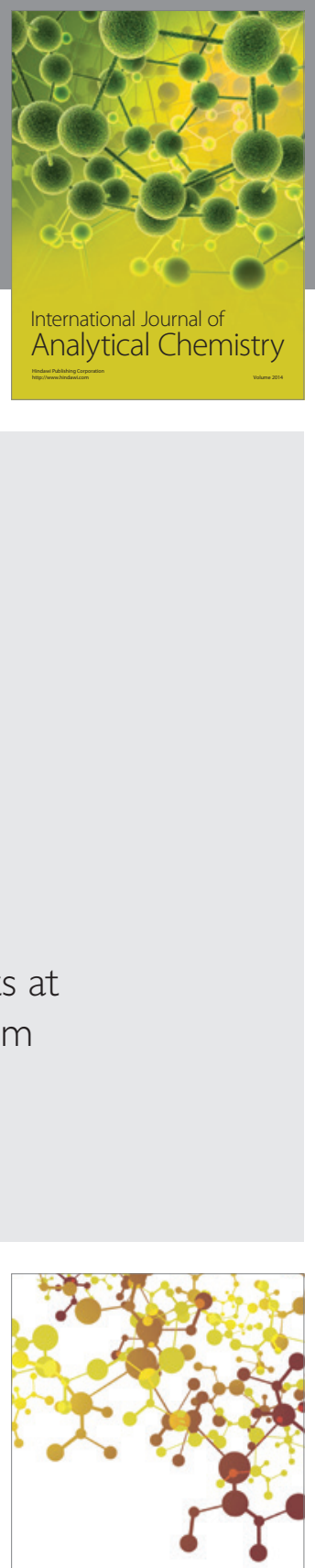

Journal of

Applied Chemistry
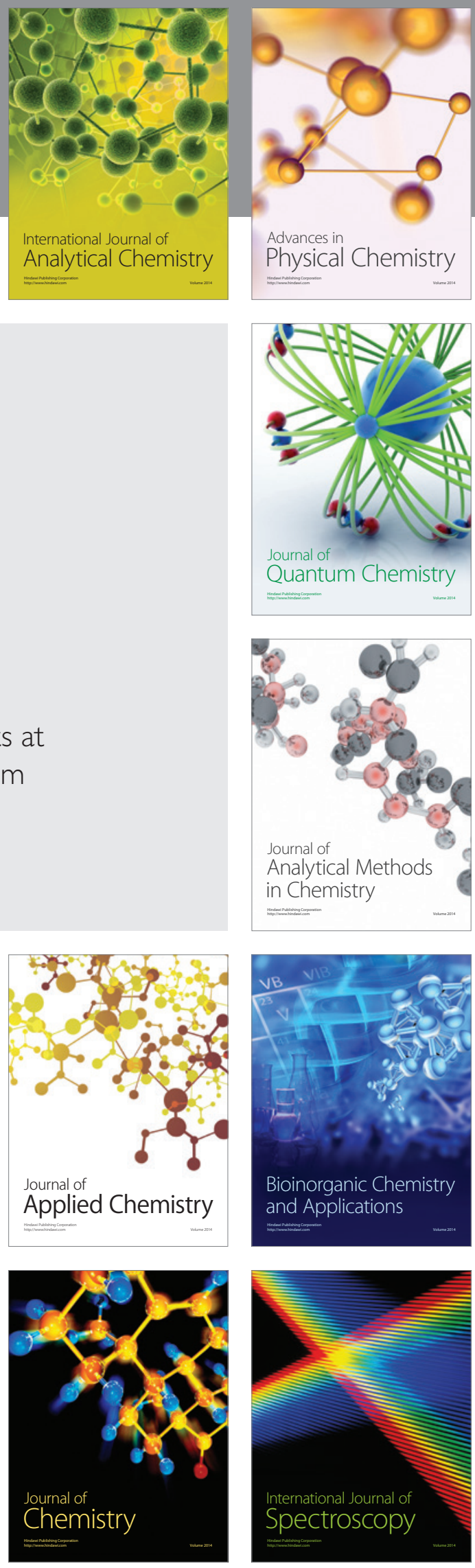